OPEN ACCESS

Edited by:

Jian Ouyang,

Dalian University of Technology, China

Reviewed by:

Zhenjun Wang,

Chang'an University, China

Wengui Li,

University of Technology Sydney,

Australia

${ }^{*}$ Correspondence:

Yunpeng Liu

liuyunpeng@whut.edu.cn

Specialty section:

This article was submitted to

Structural Materials,

a section of the journal

Frontiers in Materials

Received: 25 December 2019

Accepted: 03 April 2020

Published: 12 May 2020

Citation:

Yang C, Li J, Zhu Z, Wang S and

Liu Y (2020) Characterization

of Sulphoaluminate Cement-Asphalt

Emulsion Mortar for Cement

and Asphalt Mortar Repair.

Front. Mater. 7:101.

doi: 10.3389/fmats.2020.00101

\section{Characterization of Sulphoaluminate Cement-Asphalt Emulsion Mortar for Cement and Asphalt Mortar Repair}

\author{
Chao Yang ${ }^{1}$, Junhao $\mathrm{Li}^{1}$, Zhe Zhu' ${ }^{2}$, Shaohui Wang ${ }^{2}$ and Yunpeng Liu' ${ }^{1 *}$ \\ ${ }^{1}$ State Key Laboratory of Silicate Materials for Architectures, Wuhan University of Technology, Beijing, China, ${ }^{2}$ China \\ Building Materials Federation, Beijing, China
}

A sulpho cement-asphalt emulsion mortar was developed for the repair of damaged cement asphalt emulsion mortar. Various sulfoaluminate/Portland cement and asphalt emulsion/cement mass ratios, as well as emulsion types, were studied with respect to the setting time, rheological properties, volume stability, and mechanical properties of the repair materials in order to determine a reasonable mix proportion. The proper contents of cementitious materials and asphalt emulsion were determined. A possible relationship between the mechanical properties and the asphalt emulsion/cement mass ratio was found based on scanning electron microscopy analysis. Moreover, the shrinkage rates of the repair mortar in the fresh and hardened states showed different trends with an increase in the asphalt emulsion/cement mass ratio. The results shed light on the repair mortar for CA mortar with high efficiency and low cost.

\footnotetext{
Keywords: cement and asphalt mortar, repair mortar, sulphoaluminate cement, asphalt emulsion, high-speed railway
}

\section{INTRODUCTION}

Cement and asphalt mortar (CA mortar) is the key component of high-speed railways, supporting the weight of the slab track and train and acting as a shock-absorber (Leiben et al., 2018; Najjar et al., 2019). However, under the coupling effects of high-frequency loading and environmental erosion (Zhu et al., 2014; Fu et al., 2015; Le et al., 2019), the CA mortar tends to be damaged or broken, which significantly influences the structural and driving safety (Zhu et al., 2014; Liu et al., 2016). Therefore, this requires effective and rapid repair.

The CA mortar consists mainly of cement and asphalt emulsions. Compared with cement and concrete materials, the CA mortar is typically a low-modulus material owing to its high asphalt emulsion-to-cement ratio (usually over 0.5) (Wang et al., 2015; Liu and Liang, 2017). For example, the modulus values of the CA mortar for the Shinkansen slab (Japan) and the Max Bögl slab (Germany) were 100-300 MPa and 7,000-10,000 MPa, respectively. However, the modulus of the CA mortar for the Max Bögl slab would be $800 \sim 1,200 \mathrm{MPa}$ if tested with the same methods used for the Shinkansen slab.

Repair materials for CA mortar need to meet the following requirements considering the characteristics of the CA mortar: 
1) A balance between the workable time and the fast hardening properties: The time allowed for CA mortar repair is usually less than $4 \mathrm{~h}$; thus, repair materials must present sufficient workable time to fulfil the repair section. Moreover, they need to present fast hardening properties (such as sufficient $4 \mathrm{~h}$ mechanical properties and a short time interval between the initial and final settings of the repair materials) to guarantee the appropriate early mechanical properties.

2) Compatible modulus and strength: Repair materials for CA mortar should present mechanical properties that are compatible with those of the substrate mortar in order to ensure that the combined repair system withstands the applied stresses and maintains its structural integrity (Rangaraju, 2007). The modulus (28 days) and compressive strength (28 days) of CA mortar are 800-1,200 MPa and over $15 \mathrm{MPa}$, respectively, which are also the requirements for the repair mortar.

3) Good flowability properties: Since the CA mortar works as a shock-absorber layer between the slab track and the concrete roadbed, with a thickness of about $30-80 \mathrm{~mm}$, it should be highly flowable for grouting (Ouyang and Tan, 2015; Peng et al., 2015; Leiben et al., 2018; Ouyang and Shah, 2018). Thus, the repair mortar needs good flowability to fulfil the repair section with $D_{5} \min \geq 280 \mathrm{~mm}$ and $\mathrm{D}_{10} \min \geq 280 \mathrm{~mm}$ (the slump flow test methods of repair mortar are shown in section Mix Proportions and Experimental Design).

4) Good volume stability: The repair mortar also needs good volume stability to avoid affecting the structure height of the slab track, which is important for the safety of high-speed railways.

The most commonly used repair materials for CA mortar are resin or resin mortar, which have low modulus but are too expensive to be used widely. Moreover, our previous work (Liu et al., 2014) has shown that resin mortar may not bond well with CA mortar because of the oily and hydrophobic interface created by the high content of asphalt. Sulphoaluminate cement (SAC)-based repair materials, with good repair properties and low costs, have found wide applications and have drawn much attention in the cement and concrete repair fields. However, their modulus is too high for CA mortar repair. Some polymer latex or polymer powder has been added to cement mortar to improve its adhesive and water-proof properties (Ramli and Tabassi, 2012; Muhammad et al., 2015; Göbel et al., 2018). However, the polymer content was low (the polymer emulsion to cement mass ratio usually $0.05-0.15$ ) so that its modulus was still higher than that of CA mortar (Göbel et al., 2018) which means that it may not meet the low modulus requirements for CA mortar repair.

The purpose of this study is to develop, using high asphalt content, sulphoaluminate cement-based repair materials with low modulus and ensure the cost is kept low. The effects of key components such as cementitious materials and asphalt emulsion on the properties and microstructure of repair mortar were studied.
TABLE 1 | Composition and properties of PC and SAC cement.

\begin{tabular}{|c|c|c|}
\hline & PC & SAC \\
\hline \multicolumn{3}{|c|}{ COMPOSITION (wt, \%) } \\
\hline $\mathrm{SiO}_{2}$ & 21.46 & 6.45 \\
\hline $\mathrm{Al}_{2} \mathrm{O}_{3}$ & 5.64 & 20.58 \\
\hline $\mathrm{Fe}_{2} \mathrm{O}_{3}$ & 2.95 & 1.35 \\
\hline $\mathrm{CaO}$ & 60.59 & 43.72 \\
\hline $\mathrm{MgO}$ & 1.64 & 1.83 \\
\hline $\mathrm{SO}_{3}$ & 2.75 & 17.89 \\
\hline Ignition loss & 2.95 & 6.13 \\
\hline \multicolumn{3}{|c|}{ PHYSICAL PROPERTIES } \\
\hline Density $\left(\mathrm{g} / \mathrm{cm}^{3}\right)$ & 3.12 & 3.04 \\
\hline Surface area $\left(\mathrm{m}^{2} / \mathrm{kg}\right)$ & 349 & 282 \\
\hline \multicolumn{3}{|l|}{ Setting time (min) } \\
\hline Initial setting & 129 & 28 \\
\hline Final setting & 190 & 50 \\
\hline \multicolumn{3}{|c|}{ COMPRESSIVE STRENGTH (MPa) } \\
\hline 3 days & 24.0 & 45.2 \\
\hline 28 days & 51.7 & 50.4 \\
\hline
\end{tabular}

TABLE 2 | Properties of asphalt emulsion.

\begin{tabular}{|c|c|c|c|c|}
\hline \multirow[b]{2}{*}{$\begin{array}{l}\text { Solid } \\
\text { content/\% }\end{array}$} & \multirow[b]{2}{*}{$\begin{array}{c}\text { Sieve } \\
\text { residue/\% }\end{array}$} & \multirow[b]{2}{*}{$\begin{array}{l}\text { Storage stability } \\
\left(5 \text { days, } 25^{\circ} \mathrm{C}\right)(\%)\end{array}$} & \multicolumn{2}{|c|}{ Evaporated residue } \\
\hline & & & $\begin{array}{c}\text { Penetration } / 25^{\circ} \mathrm{C} \text {, } \\
0.1 \mathrm{~mm}\end{array}$ & $\begin{array}{l}\text { Softening } \\
\text { point } /{ }^{\circ} \mathrm{C}\end{array}$ \\
\hline 60.1 & 0 & 1.3 & 67 & 46.5 \\
\hline
\end{tabular}

\section{MATERIALS AND EXPERIMENTAL METHODS}

\section{Raw Materials}

1) Cement: Ordinary Portland cement P.O 42.5 (PC) and sulfoaluminate cement SAC 42.5 were used in this study. The composition and properties of the cements are listed in Table 1.

2) Asphalt emulsion (AE): Anionic asphalt emulsions were used in this study. The emulsifier dosage was $2.0 \%$. The properties are listed in Table 2.

3) Fine aggregate: River sand with an apparent density of $2,630 \mathrm{~kg} / \mathrm{m}^{3}$ was used. The water absorption rate was $1.8 \%$ and the mud content was $0.4 \%$.

4) The superplasticizer (SP) used was a polycarboxylic highperformance water reducer with $20.0 \%$ solid content and $26.6 \%$ water-reducing ratio.

5) The deformer (DF) used in this study was silicone based with $30.1 \%$ solid content and a $\mathrm{pH}$ value of 8.2.

\section{Mix Proportions and Experimental Design}

The experimental design is shown in Figure 1. The main objective of this study is to determine the mix proportion of repair materials, which includes the composition of dry powder and the asphalt emulsion contents. 


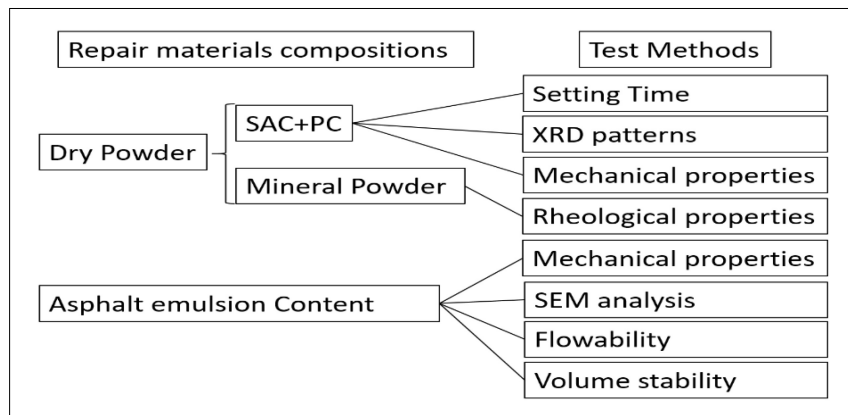

FIGURE 1 | Experimental design.

TABLE 3 | Mix proportion of sulphoaluminate cement and Portland cement.

\begin{tabular}{llllllllllll}
\hline Sample & S0 & S1 & S2 & S3 & S4 & S5 & s6 & s7 & s8 & s9 & s10 \\
\hline SAC/PC & $0: 10$ & $1: 9$ & $2: 8$ & $3: 7$ & $4: 6$ & $5: 5$ & $6: 4$ & $7: 3$ & $8: 2$ & $9: 1$ & $10: 0$
\end{tabular}

The cement-asphalt emulsion paste was prepared to investigate the effect of different $\mathrm{SAC} / \mathrm{PC}$ ratios on the setting time. The mix proportion of SAC-PC paste is shown in Table 3. The asphalt emulsion/cement ratio $(A / C)$ and water-to-cement ratio $(w / c)$ were both 0.4 . The water in the asphalt emulsion was also taken into account when calculating $w / c$.

The effect of the SAC/PC ratio on the mechanical properties of the repair mortar was studied by testing the mortar strength. The mortar was prepared with cement/standard sand mass ratio $c / s=1: 2, A / C=0.4$, and $w / c=0.4$. The superplasticizer content was $1 w t \%$ of the cementitious materials.

The mineral powders improved the rheological properties of the mortar. Two different types of mineral powder, fly ash and slag powders, were employed to prepare the SAC paste. The $w / c$ and the $A / C$ ratios were 0.4 and 0.3 , respectively.

To investigate the effect of the $A / C$ ratio on the rheological properties of the pastes, $S A C-A E$ pastes with $A / C$ ratios varying from 0 to 0.7 were prepared with $w / c=0.4$. The amount of water in the asphalt emulsion was incorporated into the calculation of the $w / c$ ratio.

According to the results above, the dry powder content of the repair materials could be determined. Then, the effects of different $A / C$ ratios on the mechanical, rheological, and volume stability properties were investigated to determine the proper $A / C$ ratio and evaluate the performance of the repair mortar.

\section{Experimental Methods}

\section{Setting Time}

The method was developed based on the standard specification for the test of setting time of cement paste (AQSIQ, 2001) and reported before (Wang et al., 2008). The paste was prepared in a mold, and every $30 \mathrm{~min}$ a steel needle penetrated the grout from the upper surface, and after $30 \mathrm{~s}$, the depth was read. The setting process can be characterized by plotting the depth against time.

\section{Slump Flow Property Tests}

The slump flow property of the repair mortar was tested according to the Chinese Railway Specification (2008). The mortar was poured into a tube (inner diameter $D=50 \mathrm{~mm}$, height $H=190 \mathrm{~mm}$ ) and its diameter was measured until the grout stopped flowing, after this the tube was elevated by $15 \mathrm{~cm}$.

\section{Rheological Properties Test}

A $350-\mathrm{mL}$ SAC-AE sample was used for rheological measurements using an R/S-SST rheometer manufactured by Brookfield (Middleboro, Massachusetts). The shear rate underwent 2 equal rounds, increasing from 0 to $150 \mathrm{~s}^{-1}$ (ascending stage) within $30 \mathrm{~s}$ and then decreasing from $150 \mathrm{~s}^{-1}$ to 0 (declining stage) within the same time.

\section{Shrinkage Test}

The expansion rate of the repair mortar in the fresh state was measured using cylinder methods, as shown in the Chinese Railway Specification (2008). The fresh repair mortar was poured into a $250 \mathrm{ml}$ graduated flask with its surface covered with plastic film to prevent moisture exchange. The initial depth of the mortar $\left(\mathrm{h}_{0}\right)$ and its depth at a different time $\left(\mathrm{h}_{t}\right)$ were measured using a Vernier caliper with a precision of $0.02 \mathrm{~mm}$. The shrinkage rate was calculated using Equation (1):

$$
P=\frac{\left(\mathrm{h}_{\mathrm{t}}-\mathrm{h}_{0}\right)}{\mathrm{h}_{0}} \times 100 \%
$$

Where $\mathrm{P}$ is the expansion rate $(\%), \mathrm{h}_{t}$ is the depth of the mortar after $\mathrm{t} \min (\mathrm{mm})$, and $\mathrm{h}_{0}$ is the initial depth after casting $(\mathrm{mm})$.

The shrinkage rate of hardened RM was measured according to the specifications of the National Development Reform Commission (2004). The mortar was prepared with dimensions of $25 \times 25 \times 280 \mathrm{~mm}$, and then cured for $24 \mathrm{~h}$ in a standard curing box at a temperature of $20 \pm 3^{\circ} \mathrm{C}$ and a relative humidity over $90 \%$. After it was cured in water at a temperature of $20 \pm 1^{\circ} \mathrm{C}$ for 2 days, the mortar was removed and wiped clean before the initial length $L_{0}$ was measured. Then, it was continuously cured in a curing box at a temperature of $20 \pm 3^{\circ} \mathrm{C}$ and a relative humidity of $50 \pm 4 \%$. The sample length at different curing times, $L_{t}$, was measured. The shrinkage rate was calculated according to Equation (2):

$$
S=\frac{\left(L_{0}-L_{t}\right) \times 100}{250}
$$

Where $\mathrm{S}$ is the shrinkage rate of the sample (\%), $L_{o}$ is the initial length of the sample $(\mathrm{mm})$, and $L_{t}$ is the sample length at different curing times (mm).

\section{Test of Mechanical Properties}

Specimens with dimensions of $40 \times 40 \times 160 \mathrm{~mm}$ were tested using a Materials Testing System with a constant loading rate of $0.05 \mathrm{KN} / \mathrm{s}$ for the flexural test and $0.5 \mathrm{KN} / \mathrm{s}$ for the compressive test according to AQSIQ (1999).

The test method of the repair mortar modulus is as follows; the sample is loaded to $800 \mathrm{~N}$ with a loading rate of $1 \mathrm{~mm} / \mathrm{min}$ and then unloaded with the same rate according to the Chinese Railway Specification (2008). This process was repeated 4 times, and the stress and strain of $3 / 4$ and $0.5 \mathrm{MPa}$ in the fifth test curve were taken and calculated as follows:

$$
E=\frac{\left(\sigma_{b}-\sigma_{a}\right) h}{b-a}
$$


Where $E$ is the modulus of the sample, $h$ is the height of the sample, $\sigma_{b}$ is the compressive strength of the $3 / 4$ part of the fifth test curve, $\sigma_{a}$ is $0.5 \mathrm{MPa}, b$ is the strain of the $3 / 4$ part in the fifth test curve, and $a$ is the strain of $0.5 \mathrm{MPa}$ in the fifth test curve.

\section{SEM Test}

The microstructure of the SAC-AE paste was examined using an S-3400N scanning electron microscope (SEM) (Hitachi, Japan).

\section{XRD Analysis}

The XRD curves of the SAC-AE paste were measured with nonmonochromatic $\mathrm{Cu} \mathrm{K} \alpha \mathrm{X}$-ray radiation at $40 \mathrm{kV}$ and $40 \mathrm{Ma}$, and recorded from $5^{\circ}(2 \theta)$ to $75^{\circ}(2 \theta)$.

\section{RESULTS AND DISCUSSION}

\section{Effect of the SAC/PC Ratio on the Setting Time of SAC/PC-AE Pastes}

The setting time of the (SAC/PC)-AE paste is shown in Figure 2. The addition of SAC significantly decreased the setting time. When the SAC content was 0 , the initial and final setting times of the pure PC-AE paste were 878 and 1,035 min, respectively. When the SAC/PC ratio was over 1:1, the setting time of the (SAC/PC)-AE paste sharply decreased. The initial and final setting times of S6 (SAC/PC ratio of 6:4) were 15 and $27 \mathrm{~min}$, respectively. Then, the setting time became stable when the SAC content further increased. This is significantly different from the SAC/PC pastes whose setting time would first decrease and then increase with the increase in the SAC content (Chen et al., 2007). The different results can be attributed to the addition of the asphalt emulsion. The setting time of the SAC/PC-AE paste is governed by both the cement hydration speed and the asphalt emulsion demulsification speed. The stable initial setting time of the composite paste indicated that the asphalt emulsion demulsification speed was the main factor controlling the setting time.

The composite cement in the wide mix proportion range would lead to a sharp decrease in the setting time. When the $\mathrm{SAC} / \mathrm{PC}$ ratio was $1: 1$, the difference between the initial and final setting times of the SAC/PC-AE paste was only $7 \mathrm{~min}$. XRD patterns (Figure 3) showed that the substitution of 50\% PC by SAC led to stronger AFt peaks and weaker $\mathrm{C}_{4} \mathrm{~A}_{3} \bar{S}$ peaks. This is because the $\mathrm{C}_{4} \mathrm{~A}_{3} \bar{S}$ in $\mathrm{SAC}$ and $\mathrm{C}_{3} \mathrm{~S}$ in $\mathrm{PC}$ have mutual promotion effects on the cement hydration process, which accelerates the setting process.

\section{Effect of the SAC/PC Ratio on the Mechanical Properties of the SAC/PC-AE Mortar}

The effect of SAC/PC on the mechanical properties of the composite paste is shown in Figure 4. As can be seen, the flexural and compressive strengths first decreased and then increased with the increase in the SAC content. The strength decreased when the SAC content varied from 20 to $80 \%$. This is because when the SAC content changed from 20 to $80 \%$ and therefore the

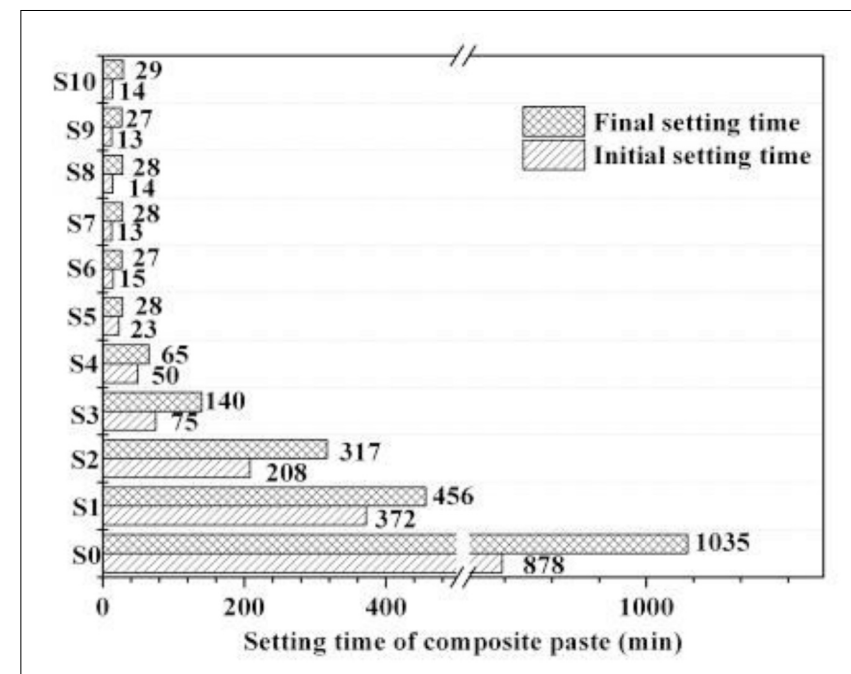

FIGURE 2 | Setting time of composite cement and asphalt emulsion paste.

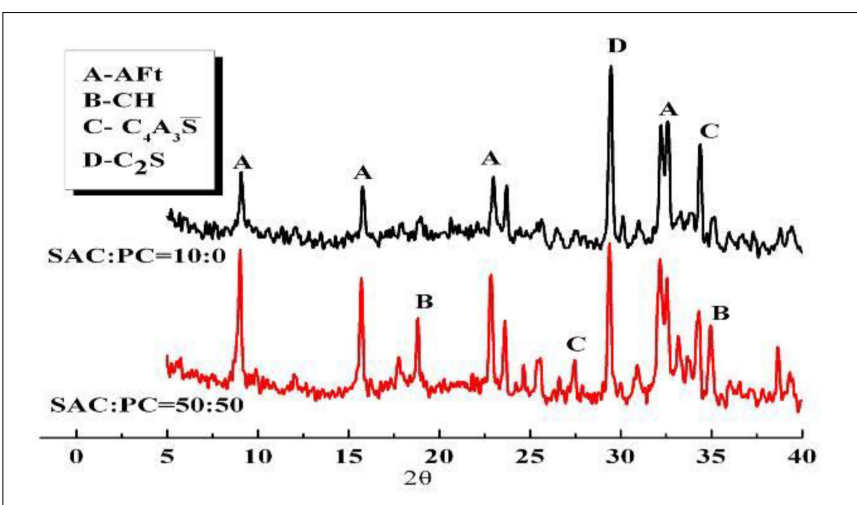

FIGURE $3 \mid X R D$ results of composite paste with different SAC/PC ratio.

SAC/PC paste showed a faster hydration speed according to the results in section Effect of the SAC/PC Ratio on the Setting Time of SAC/PC-AE Pastes. The hydration products of SAC and PC do not have enough time to form a dense microstructure, thus decreasing the compressive strength. Moreover, an obvious fast setting appeared when the SAC content was of $50-80 \%$ as shown in Figure 2. Thus, the SAC/PC ratio was $90 / 10$ when considering both the setting time and mechanical strength results.

\section{Effect of Mineral Mixture on the Rheological Properties of Sac-Ae Pastes}

Figure 5 compares the effect of the mineral mixture on the rheological properties of the SAC-AE pastes $(A / C=0.3$, $w / c=0.4)$. The curves in the ascending stage could be fitted according to the Bingham model (Peng et al., 2015) and the results are listed in Table 4. The addition of fly ash (FA) and mineral powder (MP) reduced yielding stress. The addition of $10 \%$ mineral powder (MP) showed the best improvement. This could be attributed to the improvement of the cement grain 
grading by mineral powder, which released more free water and improved the rheological properties.

\section{Effect of Asphalt Emulsion Content on the Mechanical Properties and Microstructure of Repair Mortars}

According to the above results, the composition of 1,500 kg dry powder was determined as follows: SAC $415 \mathrm{~kg}$, PC $45 \mathrm{~kg}$, mineral powder $40 \mathrm{~kg}$, and river sand 1,000 kg. The dry powder was then used to prepare the repair mortar, as shown in Table 5. The effect of the $\mathrm{A} / \mathrm{C}$ ratio on the mechanical properties of the repair mortar is shown in Figure 6.

As can be seen, the strength of the repair mortar sharply decreased with an increase in the $A / C$ ratio. The $4 \mathrm{~h}$ compressive strength of the repair mortar decreased from 16.8 to $9.6 \mathrm{MPa}$, i.e., by $42 \%$, when the $A / C$ ratio increased from 0 to 0.1 . However, when the $A / C$ ratio increased to 0.3 , the strength changed slightly. When the ratio continually increased to 0.5 , the strength decreased sharply again and slightly changed when $A / C=0.7$. The same trend could be found for the mortar at 1-56 days age. Coupling with the effect of $A / C$ ratio on the repair mortar modulus (shown in Table 5), the $A / C$ ratio is determined as 0.3 , which is compatible with the modulus of substrate CA mortar (800-1,200 MPa).

TABLE 4 | Effect of mineral material on the rheological properties of the SAC-AE paste.

\begin{tabular}{lccccc}
\hline Parameter & Control sample & FA10\% & FA20\% & MP10\% & MP20\% \\
\hline Thetat $/(\mathrm{Pa})$ & 50.53 & 31.73 & 46.00 & 7.38 & 7.82 \\
$\eta_{p l} /(\mathrm{Pa} \cdot \mathrm{S})$ & 0.76 & 0.82 & 1.14 & 0.34 & 0.35 \\
$R^{2}$ & 0.996 & 0.999 & 0.998 & 0.975 & 0.974
\end{tabular}

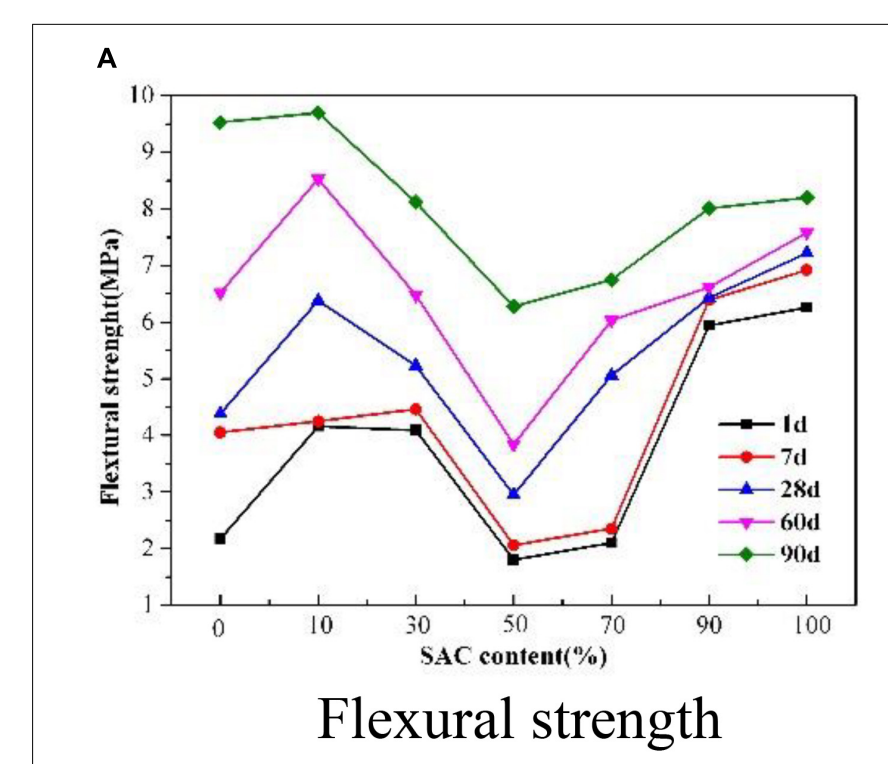

Flexural strength
Figure 7 shows the microstructure of the repair mortar with different $A / C$ ratios at $4 \mathrm{~h}$. A significant amount of needle-shaped AFt can be observed in the mortar when $A / C=0$. A small asphalt film was found on the surfaces of the hydration products when $A / C=0.1$ and 0.3 . When $A / C$ increased to 0.5 and 0.7 , most hydration product surfaces were coved with the asphalt film. It can be concluded that when the $A / C$ ratio was less than 0.3 , there was no successive asphalt film in the mortar. When the $A / C$ ratio was 0.3 , the asphalt cement ratio by volume $\left(\mathrm{V}_{A} / \mathrm{V}_{C}\right)$ was 0.91 . Ouyang's work (Ouyang et al., 2018) also showed that when $\mathrm{V}_{A} / \mathrm{V}_{C}$ was above 1 , a continuous asphalt membrane could form in the cement asphalt paste. When $V_{A} / V_{C}$ was less than 1, no conspicuous continuous asphalt membrane was observed. Therefore, the compressive strength of the SAC$\mathrm{AE}$ repair materials sharply decreased again when the $\mathrm{A} / \mathrm{C}$ ratio increased from 0.3 to 0.5 and slightly changed when $A / C=0.7$.

\section{Effect of Asphalt Emulsion Content on the Flowability of Repair Mortars}

The effect of the $A / C$ ratio on the spreading of the repair mortar is shown in Figure 8. The spreading first increased and then decreased with an increase in the $A / C$ ratio. When $A / C$ was 0.3 , the mortar had an optimum spreading of $330 \mathrm{~mm}$. The results coincided with the viscosity results of the composite cement paste shown in Figure 9. The flowability of cement paste can be improved by decreasing its apparent viscosity (Ouyang et al., 2016). Indeed, the SAC-AE paste with a decreased viscosity showed better flowability in the repair mortar. The SAC-AE paste with an $A / C$ ratio of 0.3 had the lowest viscosity; thus, the repair mortar had the optimum flowability. This could be attributed to the improvement of anionic emulsion addition on the rheological properties of the SAC-AE pastes. The zeta potentials of the anionic emulsion and SAC hydration product AFt were -70 and $+4.53 \mathrm{mV}$, respectively. When the $A / C$ ratio was 0.3 , the

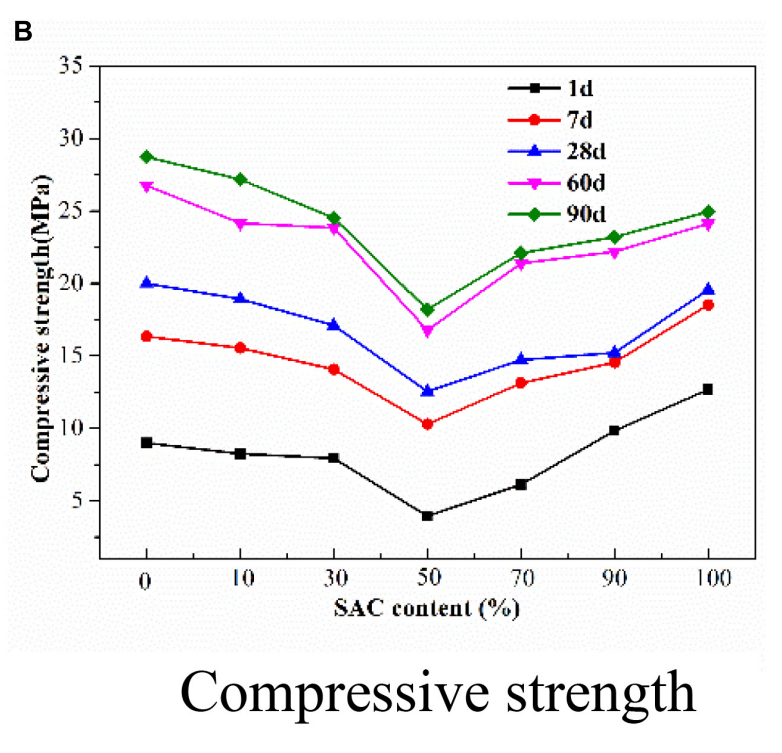

FIGURE 4 | Effect of SAC/PC on the mechanical properties of repair mortar. (A) Flexural strength. (B) Compressive strength. 
A

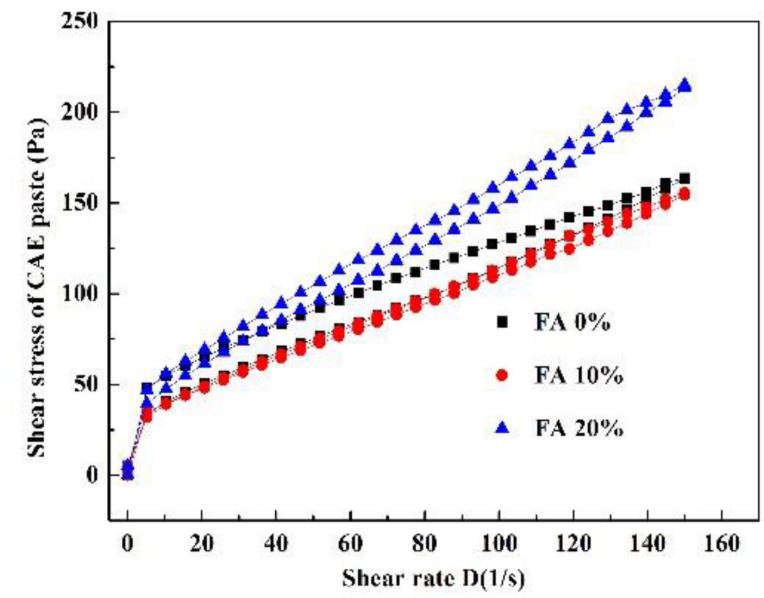

Fly ash
B

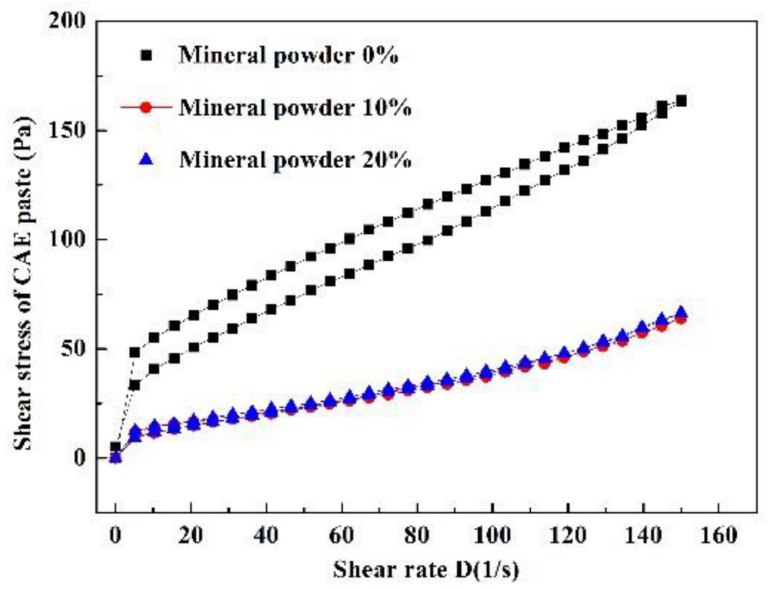

Mineral powder

FIGURE 5 | Effect of mineral material on the rheological properties of the SAC-AE paste. (A) Fly ash. (B) Mineral powder.

TABLE 5 | Modulus of repair mortar $\left(\mathrm{kg} / \mathrm{m}^{3}\right)$.

\begin{tabular}{|c|c|c|c|c|c|c|c|c|}
\hline $\mathbf{G}^{*}$ & w & $\mathrm{AE}$ & DF & SP & $\mathrm{A} / \mathrm{C}$ & $w / c$ & \multicolumn{2}{|c|}{ Modulus (MPa) } \\
\hline 1,500 & 240 & 0 & I & 8 & 0 & 0.52 & 1,495 & 1,534 \\
\hline 1,500 & 220 & 50 & 0.06 & 8 & 0.1 & 0.52 & 1,269 & 1,345 \\
\hline 1,500 & 180 & 150 & 0.10 & 8 & 0.3 & 0.52 & 961 & 1,037 \\
\hline 1,500 & 140 & 250 & 0.16 & 8 & 0.5 & 0.52 & 695 & 783 \\
\hline
\end{tabular}

* $G$ indicates the dry powder of the repair mortar.

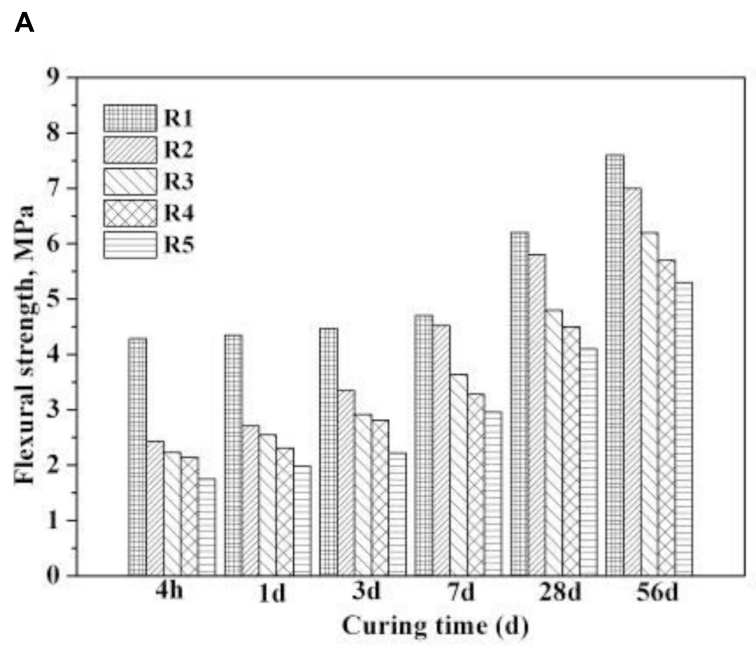

Flexural strength
B

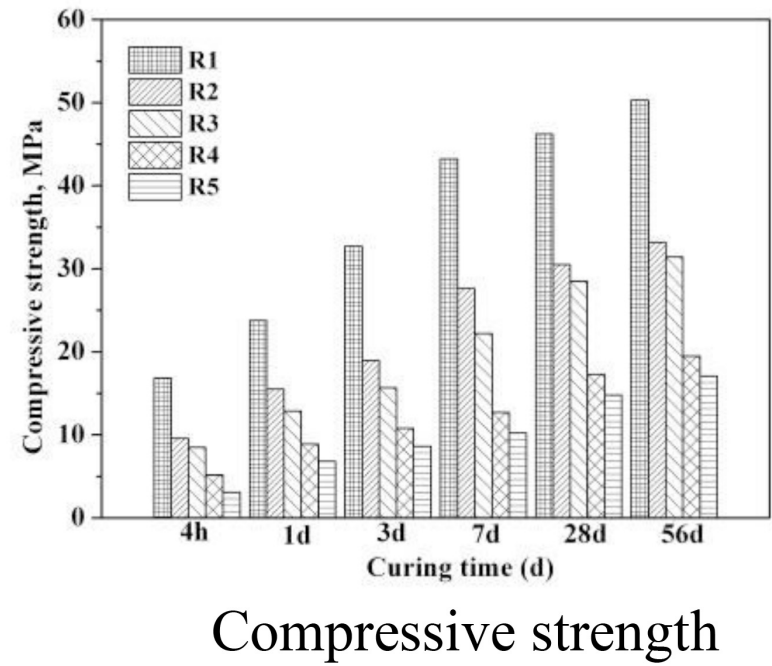

FIGURE 6 | Influence of asphalt content on the properties of repair materials. (A) Flexural strength. (B) Compressive strength. 


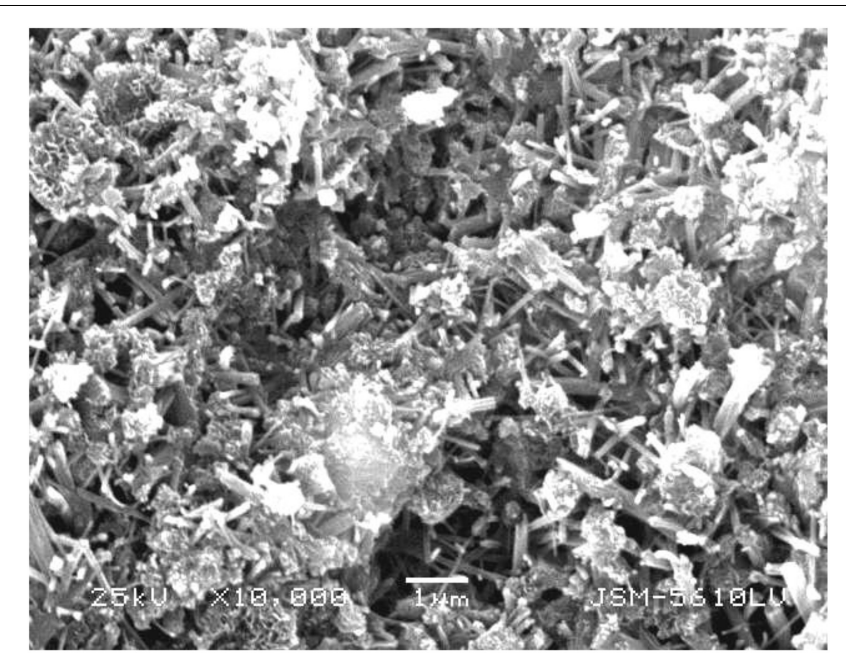
$A / C=0,10000$ times

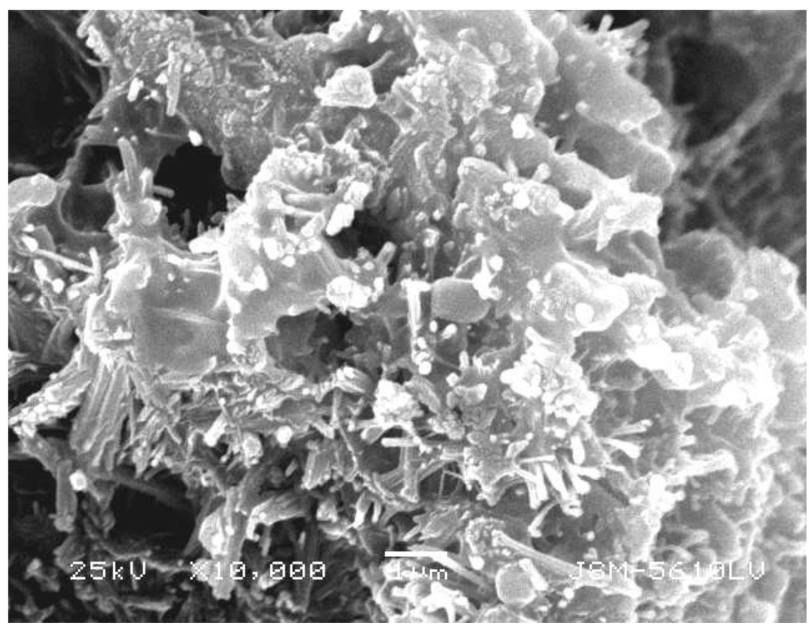

$A / C=0.3,10000$ times

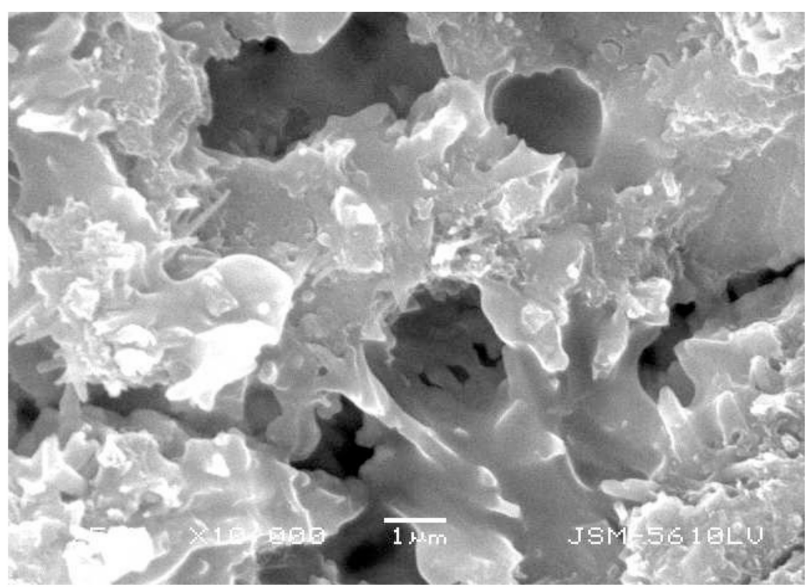

$A / C=0.7,10000$ times

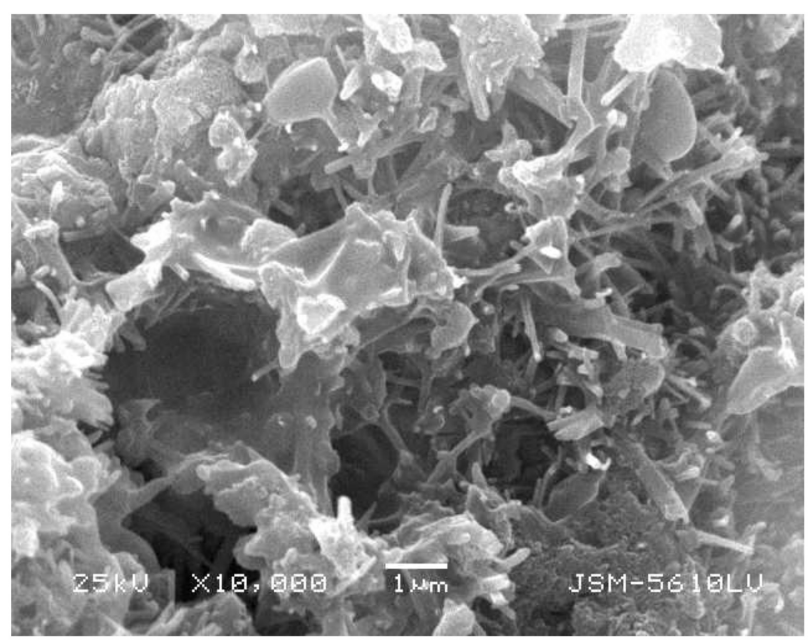

$A / C=0.1,10000$ times

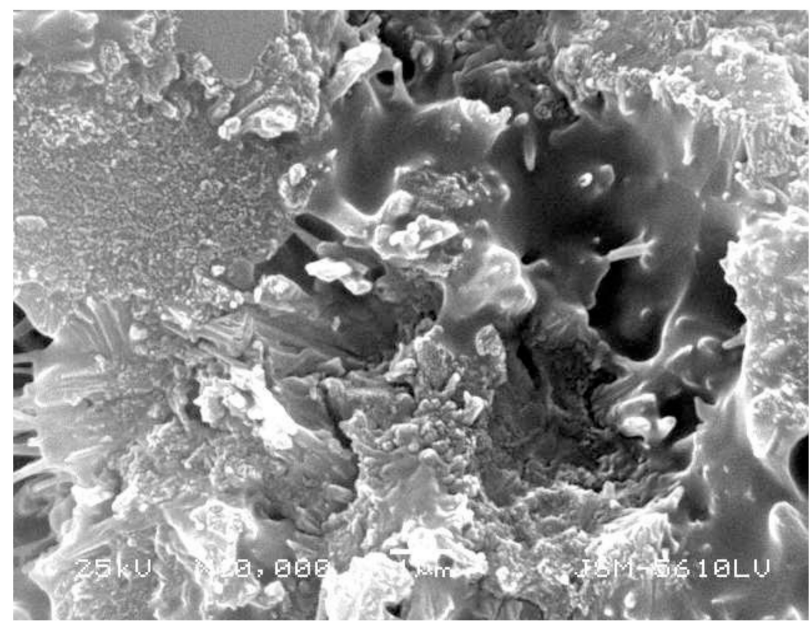

$A / C=0.5,10000$ times

FIGURE 7 | Microstructure of the repair mortar with different $A / C$ ratios (4 h). 
absorbed asphalt particles on the AFt surfaces showed a good dispersion effect and improved the rheological performance (Liu et al., 2019).

\section{Effect of Asphalt Emulsion Content on the Volume Stability of Repair Mortars}

Figure $10 \mathrm{~A}$ shows the expansion rate variation of the repair mortar with different $A / C$ ratios with $0-2 \mathrm{~h}$ curing time. As it can be seen, the expansion rate was negative, indicating that it shrank. The shrinkage rate increased with increasing $A / C$ ratio. The shrinkage of the repair mortar in the fresh state could be attributed to the quick burst of many bubbles induced by the emulsifier in the asphalt emulsion. The air content increased and density decreased (Table 6) with an increase in the $A / C$ ratio. These bubbles were burst by SAC hydration, which decreased the

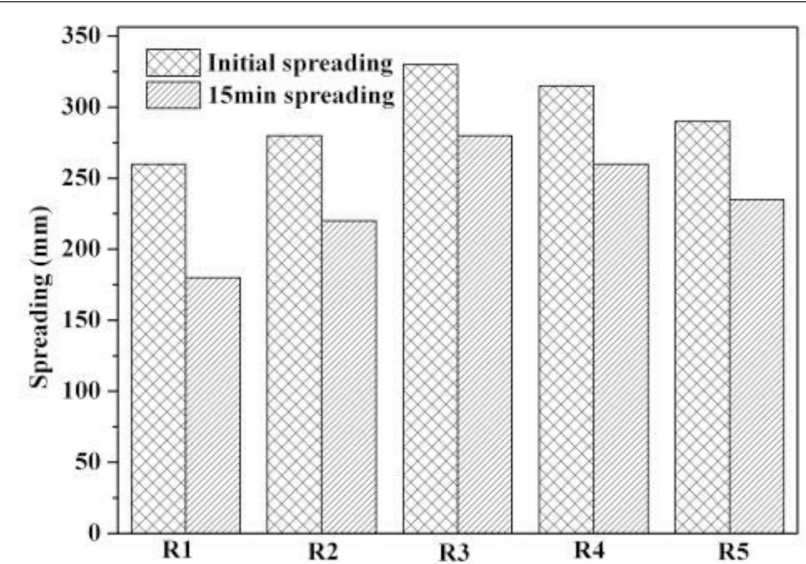

FIGURE 8 | Effect of $A / C$ ratio on the spreading properties. mortar height. When SAC continued hydration, the AFt amount increased, which made the mortar denser and thus reduced the shrinkage rate.

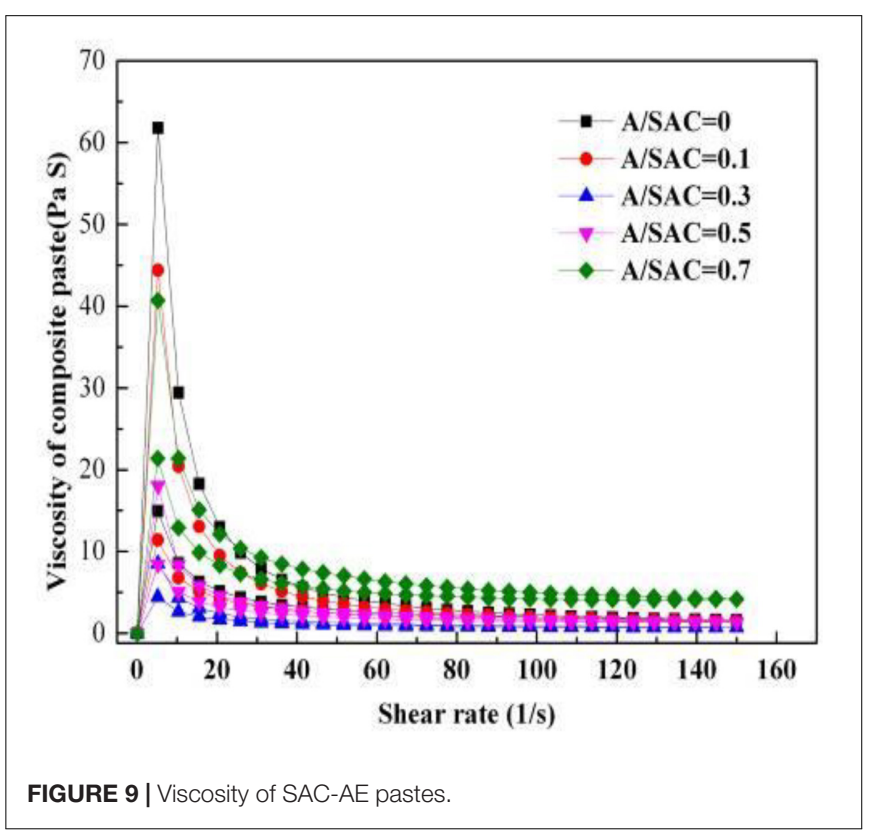

TABLE 6 | The air content of repair mortar with different $A / C$ ratios.

\begin{tabular}{lcc}
\hline No. & Density $\mathbf{( k g / \mathbf { m } ^ { \mathbf { 3 } } )}$ & Air content $\mathbf{( \% )}$ \\
\hline R1 & 2,072 & 1.5 \\
R3 & 2,010 & 2.4 \\
R5 & 1,954 & 4.2
\end{tabular}

A

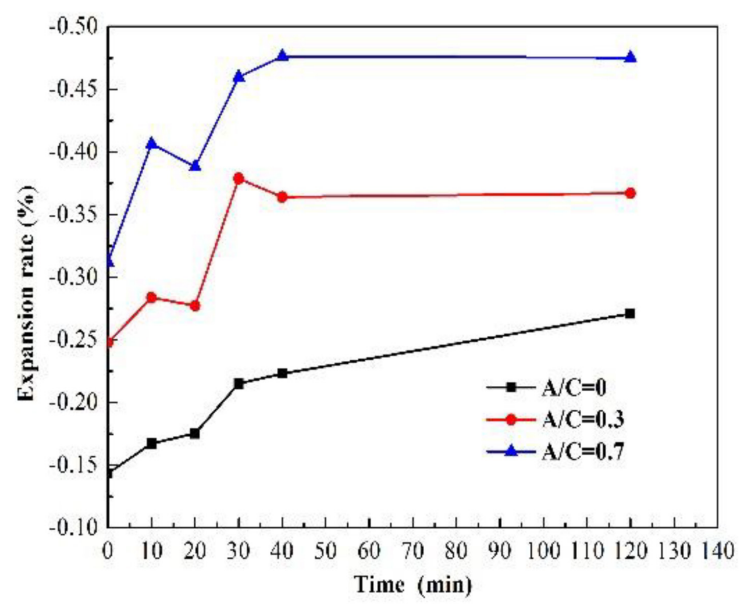

Early age time $(0-2 \mathrm{~h})$ properties
B

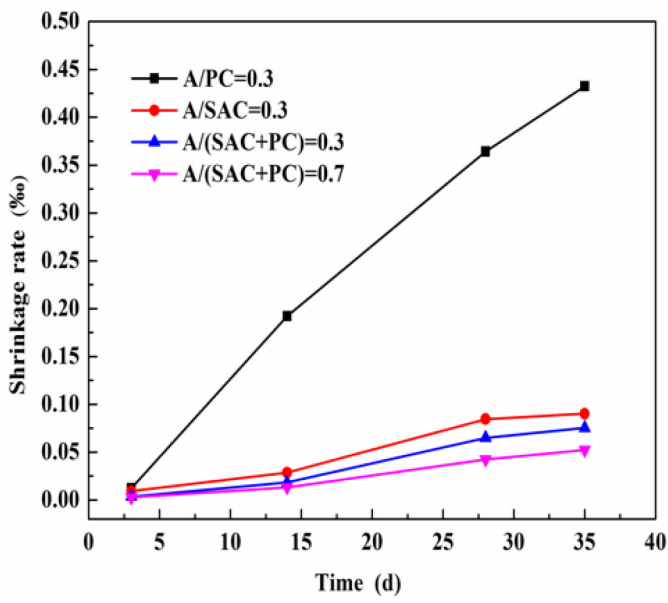

Long-term properties

FIGURE 10 | Volume stability of cement-based repair material with low modulus. (A) Early age time (0-2 h) properties. (B) Long-term properties. 
As shown in Figure 10B, the long-term shrinkage rate of repair materials decreased with an increase in the $A / C$ ratio. The mortar shrinkage was mainly caused by water evaporation in the pores. When the asphalt emulsion content increased, the asphalt droplets absorbed the surfaces of SAC and decreased the water evaporation in the pores. Moreover, this may be because the addition of an asphalt emulsion changes the pore structure in the mortar, this requires further investigation.

Figure 10B also compares the shrinkage rates of PC, SAC, and PC/SAC pastes with different curing times. As can be seen, the shrinkage rate of PC mortar increased with curing time. The SAC and SAC/PC pastes showed a lower shrinkage rate and were stable with an increase in curing time. Moreover, the SAC/PC paste showed a lower shrinkage rate. This could be attributed to the accelerating effect on cement hydration by the addition of PC. More AFt was generated in the early stages, which could compensate for the mortar shrinkage.

\section{CONCLUSION}

1) The optimum mix proportion of the repair materials was determined. The proper SAC/PC ratio was 90/10. The addition of $10 \%$ mineral powder improves the rheological properties of repair mortar. Repair mortar with an A/C ratio of 0.3 has proper mechanical properties, optimum flowability, and volume stability.

2) The composition of SAC and PC in a wide mix proportion would have an adverse effect on the setting time and strength of composite pastes due to the mutual promotion effect on $\mathrm{SAC}$ and PC hydration.

\section{REFERENCES}

AQSIQ (1999). Method of Testing Cements-Determination of Stength. Beijing: AQSIQ.

AQSIQ (2001). Test Methods for Water Requirement of Normal Consistency, Setting Time and Soundness of the Portland Cements. Beijing: AQSIQ, 346-2001.

Chen, J., Li, B. X., and Lu, Y. Y. (2007). Experimental study on the properties of OPC-SAC mixed cement. J. Chon. J. Univ. 29, 121-124.

Chinese Railway Specification (2008). Technical Specification of Cement Asphalt Emulsion Mortar for CRTSI Non-Ballast slab Track. Beijing: China Railway Publishing House.

Fu, Q., Xie, Y.-J., Long, G.-C., Meng, F., and Song, H. (2015). Temperature sensitivity and model of stress relaxation properties of cement and asphalt mortar. Constr. Build. Mater. 84, 1-11.

Göbel, L., Osburg, A., and Pichler, B. (2018). The mechanical performance of polymer-modified cement pastes at early ages: ultra-short non-aging compression tests and multiscale homogenization. Constr. Build. Mater. 173, 495-507.

Le, T. H. M., Park, D.-W., and Seo, J.-W. (2019). Evaluation on the mechanical properties of cement asphalt mortar with quick hardening admixture for railway maintenance. Constr. Build. Mater. 206, 375-384.

Leiben, Z., Wang, X., Wang, Z., Yang, B., Tian, Y., and He, R. (2018). Damping characteristics of cement asphalt emulsion mortars. Constr. Build. Mater. 173, 201-208.

Liu, B., and Liang, D. (2017). Effect of mass ratio of asphalt to cement on the properties of cement modified asphalt emulsion mortar. Constr. Build. Mater. 134, 39-43.
3) The mechanical properties and structure of the repair mortar were determined by the $A / C$ ratio. When $A / C \leq 0.3$, the asphalt droplets could not form the successive film structure and the asphalt film existed in the dispersed phase. When $A / C>0.3$, the asphalt phase changed from the dispersed phase to a successive phase.

4) The shrinkage rate of repair materials increased and decreased with an increase in the $A / C$ ratio in the early and late stages, respectively. In addition, the composite of SAC and PC could reduce the shrinkage rate, which could be attributed to accelerated SAC hydration by the addition of PC.

\section{DATA AVAILABILITY STATEMENT}

The datasets generated for this study are available on request to the corresponding author.

\section{AUTHOR CONTRIBUTIONS}

CY and JL co-wrote the manuscript. ZZ and SW contributed to the discussion part. YL designed and performed the experiments.

\section{ACKNOWLEDGMENTS}

We would like to thank the financial support from the National Natural Science Foundation of China (51972250) and Hubei Technology Innovation Key Program (2018AAA004).

Liu, Y., Wang, F., Hu, S., and Liu, M. (2016). Compatibility of repair materials with substrate low-modulus cement and asphalt mortar (CA mortar). Constr. Build. Mater. 126, 304-312.

Liu, Y., Wang, F., Liu, M., and Hu, S. (2014). A microstructural approach to adherence mechanism of cement and asphalt mortar (CA mortar) to repair materials. Constr.Build. Mater. 66, 125-131.

Liu, Y., Wang, F., Zhang, W., and Hu, S. (2019). Rheological properties of sulfoaluminate cement-asphalt emulsion paste. J. Mater. Civil Eng. 31:04018340.

Muhammad, N. Z., Keyvanfar, A., Abd Majid, M. Z., Shafaghat, A., and Mirza, J. (2015). Waterproof performance of concrete: a critical review on implemented approaches. Constr. Build. Mater. 101, 80-90.

Najjar, S., Mohammadzadeh Moghaddam, A., Sahaf, A., Rasaei Yazdani, M., and Delarami, A. (2019). Evaluation of the mixed mode (I/II) fracture toughness of cement emulsified asphalt mortar (CRTS-II) using mixture design of experiments. Constr. Build. Mater. 225, 812-828.

National Development Reform Commission (2004). Standard Test Method for Drying Shrinkage of Mortar. Beijing: National Development Reform Commission, 603.

Ouyang, J., Han, B. G., Yu, C., Zhou, W. J., and Li, W. G. (2016). The role and interaction of superplasticizer and emulsifier in fresh cement asphalt emulsion paste through rheology study. Constr. Build. Mater. 125, 643-653.

Ouyang, J., and Shah, S. P. (2018). Factors influencing the structure build-up of fresh cement asphalt emulsion paste. Road Mater. Pavement Design 19, 87-103.

Ouyang, J., and Tan, Y. (2015). Rheology of fresh cement asphalt emulsion pastes. Constr. Build. Mater. 80, 236-243.

Ouyang, J., Zhao, J. Y., and Tan, Y. Q. (2018). Modeling mechanical properties of cement asphalt emulsion mortar with different asphalt to cement ratios and temperatures. J. Mater. Civil Eng. 30:4018263. 
Peng, J., Deng, D., Huang, H., Yuan, Q., and Peng, J. (2015). Influence of superplasticizer on the rheology of fresh cement asphalt paste. Case Stud. Constr. Mater. 3, 9-18.

Ramli, M., and Tabassi, A. A. (2012). Effects of different curing regimes on engineering properties of polymer-modified mortar. J. Mater. Civil Eng. 24, 468-478.

Rangaraju, R. R. P. A. P. R. (2007). Analysis of compatibility between repair material and substrate concrete using simple beam with third point loading. J. Mater. Civil Eng. 19, 1060-1069.

Wang, F., Liu, Z., Wang, T., and Hu, S. (2008). A novel method to evaluate the setting process of cement and asphalt emulsion in CA mortar. Mater. Struct. 41, 643-647.

Wang, Z., Shu, X., Rutherford, T., Huang, B., and Clarke, D. (2015). Effects of asphalt emulsion on properties of fresh cement emulsified asphalt mortar. Constr. Build. Mater. 75, 25-30.
Zhu, S., Fu, Q., Cai, C., and Spanos, P. D. (2014). Damage evolution and dynamic response of cement asphalt mortar layer of slab track under vehicle dynamic load. Sci. China Tech. Sci. 57, 1883-1894.

Conflict of Interest: The authors declare that the research was conducted in the absence of any commercial or financial relationships that could be construed as a potential conflict of interest.

Copyright (c) 2020 Yang, Li, Zhu, Wang and Liu. This is an open-access article distributed under the terms of the Creative Commons Attribution License (CC BY). The use, distribution or reproduction in other forums is permitted, provided the original author(s) and the copyright owner(s) are credited and that the original publication in this journal is cited, in accordance with accepted academic practice. No use, distribution or reproduction is permitted which does not comply with these terms. 